УДК 630.2

ОЦЕНКА АЭРОИОННОЙ СПОСОБНОСТИ ДРЕВЕСНЫХ РАСТЕНИЙ ДЛЯ СОЗДАНИЯ ЛОКАЛЬНЫХ ФИТОЛОГИЧЕСКИХ ИНГАЛЯТОРИЕВ

Севостьянов В.А., Грязькин А.В.

ФГБОУ ВПО «Санкт-Петербургский государственный лесотехнический университет имени С.М. Кирова», Санкт-Петербург, е-mail: budhi@mail.ru, lesovod.bk.ru

Городской воздух мегаполисов (на примере г. Москвы) в результате воздействия множества факторов имеет низкий уровень ионизации, т.е. низкое качество атмосферного воздуха, это приводит к общему ухудшению здоровья населения городов. Научные данные XIX-XX веков показывают, что древесные растения способны вырабатывать аэроионы. Ранее при озеленении городов возможность повышения уровня отрицательных ионов в воздухе с помощью древесных растений не рассматривалась. В данной статье анализируются материалы по уровню аэроионизации атмосферного воздуха и зависимость его величины от видового состава древесных растений. Измерена аэроионная активность различных видов деревьев, которые произрастают в Москве и за чертой города. Анализ полученных данных показал динамику аэроионной активности древесных видов на протяжении вегетативного периода, выявил наиболее активные растения-продуценты аэроионов. Установлено повышение уровня аэроионизации воздуха в среднем в пять раз с участием основных древесных видов в отличие от фонового уровня ионизации воздуха на участках без древесной растительности. Проведенное исследование подтвердило гипотезу о целесообразности применения при озеленении населенных мест такими древесными растениями, которые могут повышать уровень аэроионизации воздуха.

Ключевые слова: аэроионизация, отрицательные ионы воздуха, аэроионная активность зеленых насаждений, древесные породы, ионный состав воздуха, качество воздуха, гигиеническая роль леса

\title{
ASSESSMENT OF AERO IONIC ABILITY OF WOOD PLANTS FOR CREATION LOCAL PHYTOLOGICAL INHALATORIUMS
}

\author{
Sevostyanov V.A., Gryazkin A.V. \\ St. Petersburg State Timber University of S.M. Kirov, St. Petersburg, \\ e-mail:budhi@mail.ru,lesovod.bk.ru
}

\begin{abstract}
City air of megalopolises (on the example of Moscow) as a result of influence of a set of factors has the low level of ionization, i.e. poor quality of atmospheric air, it leads to the general deterioration in health of the population of the cities. Scientific data of the 19-20 th centuries show that wood plants are capable to develop aero ions. Earlier, when gardening the cities the possibility of increase of level of negative ions in air by means of wood plants wasn't considered. In this article materials on the level of aero ionization of atmospheric air and dependence of his size on specific structure of wood plants are analyzed. Aero ionic activity of different types of trees which grow in Moscow and behind city boundaries is measured. The analysis of the obtained data has shown dynamics of aero ionic activity of wood types throughout the vegetative period, has revealed the most active plants producers of aero ions. Increase of level of aero ionization of air on average five times with participation of the main wood types unlike the background level of ionization of air on sites without wood vegetation is established. The conducted research has confirmed a hypothesis of expediency of application when gardening of the inhabited places of such wood plants which can increase air aero ionization level.
\end{abstract}

Keywords: aero ionization, negative ions of air, aero ionic activity of green plantings, tree species, ionic composition of air, quality of air, hygienic role of the wood

Попытки оценить «невесомые» полезности леса исследователями предпринимались многократно. Главное направление таких исследований - гигиеническая роль леса $[5,11,12,13]$. Атмосферный воздух - один из важнейших компонентов окружающей среды. Поддержание чистоты воздуха необходимо для обеспечения благоприятных условий труда, отдыха и жизни человека сегодня и в будущем [7]. Ионный состав воздушных масс, согласно ГОСТ 12.1.0003-74 «Вредные и опасные факторы производства», относится к группе физических факторов и является одним из важнейших показателей состояния атмосферного воздуха [9].
Согласно данным Мосэкомониторинга в 2015 г. индекс загрязнения московского воздуха является недопустимо высоким 9,9 усл. единиц (при норме 5 единиц); ситуация кризисная - уровень ионизированности

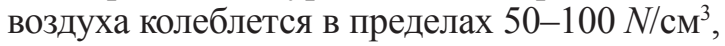
т.е. примерно на порядок ниже нормы. Существующие объемы московских зеленых насаждений не справляются с антропогенными нагрузками, несмотря на то, что взрослое дерево способно за год поглотить объем отработанных автомобильных газов, эквивалентных 25000 км пробега. Над городскими зелеными массивами летом преобладают нисходящие воздушные потоки, которые увлекают за собой скопившуюся 
в атмосфере пыль и осаждают ее на кронах деревьев и кустарников. Известно, что каждый гектар хвойных деревьев способен задерживать за год до 40 т пыли, а лиственных - свыше 100 т [4].

По статистике кафедры коммунальной гигиены Российской медицинской академии Росздрава каждый житель Москвы не доживает только за счет загрязненного воздуха один год. Ежегодно 3,5 тысяч человек в Москве умирают, еще 250 москвичей заболевают раком из-за низкого качества атмосферного воздуха [6].

По СанПиН 2.2.5.1295-03, уровень ионизации воздуха должен находиться в пределах от 600 до $5000 \mathrm{~N}-\mathrm{cm}^{3}$. Для человека является опасным отклонение в меньшую сторону от приведенного диапазона значений. Косвенно эти нормы имеют отношение и к атмосфере [4].

Еще в 20-е годы XX века было сформулировано предположение, согласно которому качество воздуха напрямую связано с уровнем его ионизации, играющим важнейшую роль при оценке гигиеничности воздушной среды, как в природных условиях, так и в закрытых помещениях [14].

Аэроионный режим традиционно считается важнейшим критерием качества природных воздушных масс и воздуха в закрытых помещениях [8]. Большинство наблюдений свидетельствуют о наличии зависимости между уровнем ионизации воздуха и состоянием человеческого организма - концентрация ионов выше максимально допустимого и ниже минимально необходимого уровня создает угрозу для здоровья человека [9].

По данным, полученным А.А. Минхом, Ю.Д. Губернским, А.Л. Чижевским, в загрязненном воздухе крупных промышленных городов и в плохо проветриваемых помещениях наблюдается резкое увеличение количества тяжелых ионов и снижение концентрации легких. Характер и степень ионизированности воздуха могут выступать в качестве косвенного показателя гигиенического состояния воздуха (Цитируется по В.П. Скипетрову, 1997) [10].

Одним из наиболее рациональных способов нормализации воздушной среды крупных мегаполисов является создание локальных зеленых насаждений, которые способны продуцировать качественные составляющие атмосферного воздуха - аэроионы и фитонциды. Значение фитонцидов подробно рассматривается уже много десятилетий, это направление поддерживается и многими современными исследователями $[4,5,11,13]$. Данная статья посвящена изучению аэроионной способности древесных растений.

В прошлом это научное направление наиболее интенсивно разрабатывалось в 50-70-е гг. XX века Л.Л. Васильевым (1953), Н.П. Тверской (1955); А.А. Минхом (1958); С.М. Чубинским (1959); Ф.Г. Портновым (1961); С.П. Финогеновым (1961); А.П. Сверчковым (1963). Согласно их наблюдениям, в атмосферном воздухе одни виды растений увеличивают число тяжелых ионов, а другие - легких [10].

И.А. Хмелевская, проведя в 2007 году комплексные эколого-физиологические исследования пород деревьев, пришла к выводу, что наибольшим эффектом ионизации отличаются сосна, ель обыкновенная, туя, дуб черешчатый, тополь черный, лиственница сибирская, рябина обыкновенная, сирень [15]. При этом наибольшую оздоровительную роль играют смешанные насаждения, то есть состоящие из разных видов хвойных и лиственных пород. Способствуют повышению концентрации легких ионов в воздухе акация белая, береза карельская, дуб красный и черешчатый, ива белая и плакучая, лиственница сибирская, пихта сибирская, рябина обыкновенная, сирень обыкновенная, тополь черный.

Целью данной работы является подтверждение гипотезы о том, что при оценке полезных функций древесных растений, используемых для озеленения городов, необходимо выявлять такие древесные виды, которые способствуют формированию требуемого уровня ионизированности атмосферного воздуха.

\section{Материалы и методы исследования}

Для выбора объектов исследования были сформированы следующие критерии:

1. Исследуемый объект на основании МГСН 1.02-02 должен входить в перечень древесных растений, применяемых для озеленения г. Москвы.

2. Исследуемый объект должен иметь объем вегетативной массы, необходимый для максимального продуцирования аэроионов.

3. Исследуемые объекты в группах должны иметь одинаковый возраст и видовую однородность.

4. Исследуемый объект должен быть широко представлен среди древесных насаждений г. Москвы, при этом он должен находиться в непосредственной близости от других исследуемых объектов, для обеспечения равномерного уровня ионизации в группе.

Согласно приведенным выше критериям отбора для проведения исследований были выбраны следующие виды древесных растений:

1. Береза повислая ( Bétula péndula Roth.).

2. Ива ломкая ( Sálix fragílis L.). 
3. Дуб черешчатый (Quércus róbur L.).

4. Клен остролистный (Ácer platanoídes L.)

5. Клен ясенелистный (Acer negúndo L.)

6. Каштан конский (Aesculus hippocastanum L.)

7. Липа мелколистная или сердцевидная (Tília cordáta Mill.).

8. Рябина обыкновенная (Sórbus aucupária L.)

9. Сосна обыкновенная (Pínus sylvéstris L.)

10. Лиственница сибирская (Lárix sibírica Ledeb.)

Объекты исследований обладают следующими характеристиками:

Береза повислая - моногруппа из 10 растений, диаметр кроны 3,5-4 м, диаметр ствола 37-42 см. Протяженность штамба 1,3-1,5 м. Расстояние между деревьями 6-8 м.

Ива ломкая - моногруппа из 5 растений, диаметр кроны 4-4,5 м, диаметр ствола 15-19 см. Протяженность штамба 1,3-1,5 м. Расстояние между стволами 4-6 м.

Дуб черешчатый - моногруппа из 15 растений, диаметр кроны 6-8 м, диаметр ствола 50-70 см. Протяженность штамба 3-4 м. Расстояние между стволами 8-11 м.

Клен остролистный - моногруппа из 7 растений, диаметр кроны 3,5-4 м, диаметр ствола 17-25 см. Низ кроны на расстоянии 1,5-2 м. Расстояние между стволами 5-8 м.

Клен ясенелистный - моногруппа из 10 растений, диаметр кроны 3,5-4 м, диаметр ствола 17 25 см. Протяженность штамба 1,5-2 м. Расстояние между стволами 5-6 м.

Каштан конский - моногруппа из 8 растений, диаметр кроны 4-5 м, диаметр ствола 27-35 см. Протяженность штамба 2-2,5 м. Расстояние между стволами 6-8 м.

Липа мелколистная - моногруппа из 7 растений, диаметр кроны 4-4,5 м, диаметр ствола 15-22 см. Протяженность штамба 1,5-1,8 м. Расстояние между стволами 5-7 м.

Рябина обыкновенная - моногруппа из 11 растений, диаметр кроны 3,5-4 м, диаметр ствола 13-16 см. Протяженность штамба 1,4-1,6 м. Расстояние между стволами 4-6 м.

Сосна обыкновенная - моногруппа из 14 растений, диаметр кроны 4-5 м, диаметр ствола 35-40 см. Протяженность штамба 2-2,8 м. Расстояние между стволами $12-14$ м.

Лиственница сибирская - моногруппа из 6 растений, диаметр кроны 3-3,5 м, диаметр ствола 15-17 см. Протяженность штамба 1,2-1,5 м. Расстояние между стволами 4-6 м.

Методы исследования

Измерение уровней ионизации проводилось в соответствии с ГОСТ [2] на территории Москвы на 4-х опытных участках:

Участок № 1 (контроль): местонахождение: г. Москва, Восточный административный округ, фрагмент Измайловского парка. Площадь участка: 1,08 га. Рельеф участка преимущественно плоский, с уклоном $1 \%$ с севера на юг и $1 \%$ с запада на восток. Представлены все объекты исследования.

Участок № 2: местонахождение: г. Москва, Восточный административный округ, Сиреневый бульвар, фрагмент от пересечения с 9-й до пересечения c 15-й Парковой улицей. Площадь участка: 6,21 га. Рельеф участка преимущественно плоский, с уклоном $2 \%$ с севера на юг и $0,001 \%$ с запада на восток.

Участок № 3: местонахождение: г. Москва, Восточный административный округ, Щелковское шос- се, фрагмент от пересечения с 9-й до пересечения с 15-й Парковой улицей. Площадь участка: 7,41 га. Рельеф участка преимущественно плоский, с уклоном $1,6 \%$ с севера на юг и $0,006 \%$ с запада на восток.

Участок № 4: местонахождение: г. Москва, Восточный административный округ, Советская улица (участок был представлен заасфальтированной территорией без древесных растений). Площадь участка: 20,4 га. Рельеф участка преимущественно плоский, с уклоном $0,02 \%$ с севера на юг и $0,001 \%$ с запада на восток.

Исследования проводились в течение активного периода вегетации $(01,06-30,08)$ с 2013 по 2015 г.

Измерения влажности и температуры воздуха, инсоляции, скорости ветра были проведены согласно Руководству по контролю загрязнения атмосферы РД 52.04.187-89 Росгидромета РФ и ГОСТ Р ИСО 57252-2002 [2]. Концентрация аэроионов измерялась с помощью метода аспирационного конденсатора $[1,3]$.

При полевых исследованиях съемка показаний измерительных приборов осуществлялась поэтапно:

1. Осуществляется выезд на указанные опытные участки и, с помощью спутникового GPSнавигатора и карты местности, определяются границы опытных участков на местности, точки размещения измерительного оборудования для будущей съемки данных, фиксируя глобальные координаты точек стояния с дисплея спутникового GPSнавигатора в журнал измерений.

2. В соответствии с графиком измерений, в день измерений, в 12-00 Мск, измерительное оборудование размещается в соответствующих, ранее определенных координатах опытных участков, снимаются показания измерительных приборов по следующей схеме: на каждом опытном участке выбирается растительная группировка одного древесного вида из исследуемого списка пород.

3. Приборы в составе: психрометр, счетчик аэроионов, анемометр и электротермометр - устанавливаются на штативы в точке съемки показаний (в центре растительной группировки) одновременно.

4. Высота установки приборов на штатив -1 м. После установки приборов в течение 1 минуты происходит их автокалибровка. После автокалибровки выполняется цикл снятия показаний с приборов. Кратность циклов: 3. Интервал между циклами: 1 минута. Снятые показания усредняются и заносятся в журнал измерений.

5. После снятия показаний с растительной группировки одного вида измерительное оборудование перемещается к растительной группировке другого вида в пределах одного ОУ и процедура действий повторяется.

При камеральной обработке данных, собранных с опытных участков, они были подвергнуты статистическому анализу с использованием программы Microsoft EXCEL 2007, с применением корреляционного и регрессивного методов.

Методом параметрической статистики получены результаты доверительного коэффициента Стьюдента, с обязательной проверкой статистической достоверности (репрезентативности) сравниваемых признаков.

Также полученные данные обработаны с использованием методов вариационной статистики, с расчетом достоверности различий сравниваемых величин. Достоверность отклонений каждой величины от средневзвешенной рассчитана с вероятностью $0.95(\mathrm{P}<0,05)$. 
Результаты исследования и их обсуждение

На участке, где полностью отсутствуют зеленые насаждения, показатели уровня аэроионизации составляют: $N+=120$ ион $/ \mathrm{cm}^{3}$, $N-=94$ ион $/ \mathrm{cm}^{3}$ и $N \pm=214$ ион $/ \mathrm{cm}^{3}$. Воздействие растительных объектов на ионизацию воздуха на опытных участках в виде усредненных показателей представлено на рис. 1.

Здесь фиолетовые столбцы - фоновые показатели аэроионного уровня на территории с отсутствием древесной растительности, синие столбцы - показатели аэроионного уровня на лесопарковой территории, содержащей исследуемые виды. Анализ полученных данных показывает, что наиболее эффективные продуценты отрицательных аэроионов: дуб черешчатый, сосна обыкновенная и ива ломкая. Породы с минимальной эффективностью продуцирования отрицательных аэроионов: липа мелколистная, клен остролистный и каштан конский.

Динамика аэроионной способности объектов наблюдений в течение вегетационного периода отражена на рис. 2.

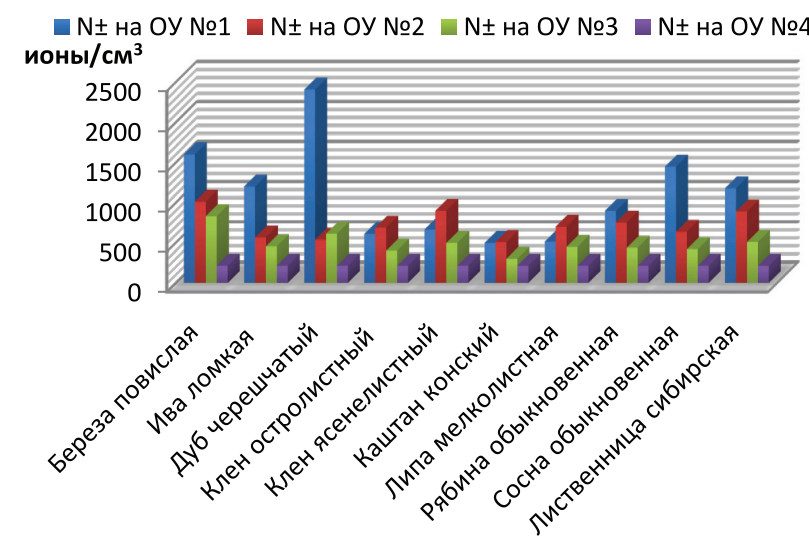

Рис. 1. Уровень максимальной ионизации воздуха для каждого исследуемого вида на опытных участках

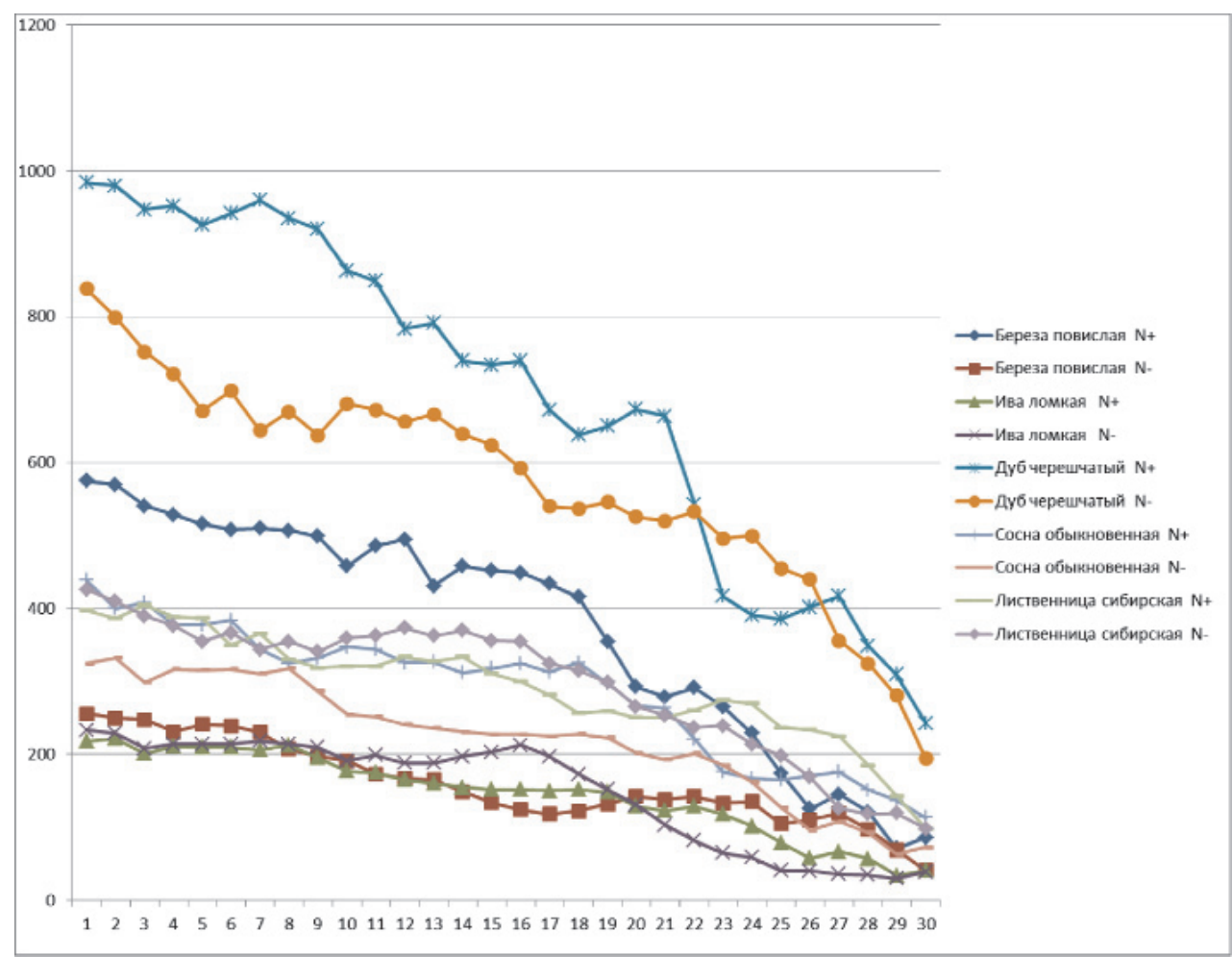

Рис. 2. Угасание аэроионной способности древесных растений в течение вегетационного периода (вертикальная ось $-N \pm / \mathrm{cm}^{3}$, горизонтальная ось - порядковый номер измерений с интервалом в три дня). Усредненные показатели трех участков 
Как видно, в период интенсивного роста (начало вегетации) растения обладают максимальной способностью продуцировать аэроионы. При этом выделяются древесные породы со стабильной аэроионной продуктивностью (береза, ива), когда количество

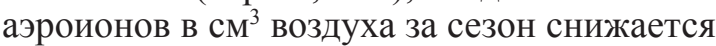
с 210 до 50-80, и породы с резко выраженной динамикой (дуб), когда наблюдается резкое снижение количества аэроинов за сезон, с 980 до 230 ионов/ $\mathrm{cm}^{3}$.

В ходе исследований установлено:

1. На протяжении всего вегетационного периода способность всех объектов наблюдений продуцировать аэроионы понижается в течение вегетационного периода, что связано с оседанием на листву и хвою атмосферной пыли и смога.

2. У сосны обыкновенной, в силу круглогодичной охвоенности побегов, способность к продуцированию аэроионов сохраняется даже при окончании периода вегетации.

3. Репрезентативность эксперимента подтверждается корреляционным анализом, в ходе которого установлено наличие статистически сильной линейной зависимости данных за 2009 и 2010 гг. Коэффициент корреляции Пирсона для данных за эти два года составляет 0,91 .

4. Корреляционный анализ массива данных, собранных в летний период показывает, что линейная зависимость между метеорологическими данными и уровнем аэроионной активности практически отсутствует для всех пород деревьев.

5. Регрессионный анализ временного ряда изменения аэроионной активности в течение летнего периода показал тенденцию к её уменьшению с течением времени как на урбанизированных участках, так и на контрольном участке, расположенном на территории парка.

\section{Выводы}

1. Примененные методы исследований эффективны для выявления растений - продуцентов аэроионов, значительно повышающих уровень ионизации воздушных масс в условиях современного промышленного центра. Наиболее продуктивными являются дуб черешчатый, лиственница сибирская, рябина обыкновенная, сосна обыкновенная.
2. Уровень ионизации атмосферы в лесопарках (опытный участок № 1) значительно выше, чем на бульварах и улицах (опытные участки № 2, 3).

3. Гипотеза о способности древесных растений продуцировать аэроионы в концентрациях, превышающих фоновые в 2-10 раз и тем самым значительно улучшающих ионный состав городского воздуха, подтверждается.

4. Так как ионизация воздуха не включена в число факторов, которые учитываются на станциях и постах Гидрометеобюро, целесообразно осуществлять мониторинг по данному показателю на территории крупных городов. Уровень аэроионизации необходимо учитывать при комплексной гигиенической характеристике населенных пунктов.

\section{Список литературы}

1. ГОСТ Р 8.845-2013. Метод измерений объемной плотности электрического заряда воздуха и счетной концентрации легких аэроионов на основе аспирационного конденсатора. - М., 2013. - C. 23-26.

2. ГОСТ Р ИСО 5725-2-2002. Часть 2. Основной метод определения повторяемости и воспроизводимости стандартного метода измерений. - М., 2002. - С. 14-17.

3. ИСО 15900:2009. Определение гранулометрического состава. Анализ дифференциальной подвижности частиц аэрозолей в электрическом поле. - М.: 2009. - С. 5-11.

4. Дмитриев С.М. Фитонциды в жизни человека. - М., 2001. - С. 207-213.

5. Зеленое пространство крупных городов: наука и инновации // Отв. Редакторы А.В. Грязькин, Н.В. Беляева. СПб.: СПбГЛТУ, 2013. - 124 с.

6. Конверс У. Сущность озона. - Нью Йорк, 1998. C. $164-170$.

7. Об охране атмосферного воздуха: Федер. закон РФ от 04.05.1999 № 96-Ф3. - М.: Российская газета, 1999. - 11 с.

8. Реута В.П. Из жизни атмосферных ионов. - М., 2005. - C. $163-167$

9. Рождественский Л.М. Краткий обзор основных аспектов применения аэроионов. - М., 2003. - С. 243-248.

10. Скипетров В.П. Аэроионы и жизнь. - М., 2003. - 197 с.

11. Слепых В.В. Фитонцидные и ионизирующие свойства древесной растительности. - Кисловодск, 2009. - 180 с.

12. Токин Б.П. Фитонциды. - М., 1948. - 178 с.

13. Токин Б.П. Целебные яды растений. - Л., 1980. $-280 \mathrm{c}$

14. Чижевский А.Л. Аэроионизация в народном хозяйстве. - М., 1938. - С. 94-96.

15. Хмелевская И.А. Эколого-физиологические исследования древесных пород в г. Пскове // Вестник Псковского государственного педагогического университета: Серия «Естественные и физико-математические науки». - 2008. № 6. - C. 37-57. 